\title{
CHALLENGES FOR NOVEL LEAD-FREE ALLOYS IN HYDRAULICS
}

\author{
Björn Reetz*, Tileman Münch \\ OTTO FUCHS Dülken GmbH\&Co.KG, Heiligenstraße 70, D-41751 Viersen \\ * Corresponding author: Tel.: +49 2162 9567738; E-mail address: bjoern.reetz@otto-fuchs.com
}

\begin{abstract}
Different special brass (e.g. CuZn37Mn3Al2PbSi) and bronze alloys (e.g. CuPb15Sn) are well known for use in oil-hydraulics having in common to be alloyed with lead. The lead content of special brass alloys in this use ranges from 0.1 to 2.0 mass- $\%$. Some bronze alloys provide even much higher contents of lead of 10 to 15 mass- $\%$. Typically, lead is considered for improvement of machinability or castability. Beyond this purpose lead in brass and bronze alloys affects many more properties of manufacturing and application. During the shaping of the parts by means of hot or cold forming often the materials are strained close to their limits. Thanks to lead cracking is prevented during this process. Lead is also of great importance for the improvement of tribological systems. The surfaces of these systems are exposed to friction and wear. Lead is incorporated in the surface layers and supports the tribological system in their running-in process to achieve a steady state of friction and wear.

Above all lead is unique because it forms no solid solution with copper or brass and forms no compounds with other typical copper alloying elements. The feasibility assessment of elements in order to substitute lead in brass or bronze alloys has to be done for each alloy and application individually. In oil-hydraulic applications as bushings, slippers or distributor plates, lead-free alloys must fulfil different profiles of requirements, depending on the conditions of manufacturing and application. The requirements do not only include mechanical strength, formability and thermal strength, but also fatigue strength, low friction and high wear resistance and lubricant compatibility.

Consequently, the substitution of lead in brass and bronze alloys for application in oil-hydraulics is a challenging task. This does not only apply for the requirements for machining and forming, but particularly for the need of the new alloys to function under wear, friction and corrosion. Examples are given for how these challenges of new lead-free special brass alloys can be met in bushings (machining, friction properties), slippers (forming, strength) and distributor plates (fatigue strength) for axial piston pumps. Further on, new lead-free special brass alloys for contact with environmentally compatible lubricants are presented. All these examples show that there is not the one and only lead-free alloy for applications in oil-hydraulics. In fact, every application requires a different alloy which is composed and processed individually to meet the specific demands.
\end{abstract}

Keywords: Special brass alloys, lead free, axial piston pump, slipper, bushings, valve plates, challenges

\section{INTRODUCTION}

Typically, copper alloys for oil-hydraulics are alloyed with more than 0.1 mass- $\%$ lead. The content of lead ranges from 0.1 to 2 mass- $\%$ in special brass alloys (e.g. CuZn37Mn3Al2Pb Si), up to 3.5 mass- $\%$ in brass alloys for machining and even up to 23 mass- $\%$ in lead bronze alloys. Special brass is brought into final shape by hot and cold forming.

Since the European Commission has endorsed the decision to classify lead as Toxic to Reproduction, producers and consumers of copper alloys are becoming more and more active to develop and to validate alternative lead-free copper alloys. This is also the case of application in oil-hydraulics where alloys once validated and used for decades are to be replaced.

Reason enough to look on the impact of lead on microstructures and properties of these alloys, before going into any specific examples for the substitution of lead. 


\section{IMPACT OF LEAD ON MANUFACTURING AND APPLICATION PROPERTIES OF COPPER ALLOYS}

The improvement of machinability is regarded as being the primary effect of lead. Chip breaking is supported because lead is insoluble and forms precipitations.

Beyond that, lead affects many other properties of copper alloys [1]:

- In casting copper alloys, lead migrates into micropores increasing the density of the cast product.

- Lead contributes to grain refinement of copper alloys which results in an increase of strength and toughness of these alloys [2].

- Investigations on machining brass indicate that lead also affects relaxation strength of brass alloys positively [3].

- Trials with CuZn42have shown the formation of microcracks. This effect was not encountered with $\mathrm{CuZn} 40 \mathrm{~Pb} 2$ [3].

- Enhanced use of bio-compatible lubricants provokes dezincification or stress corrosion cracking of parts made of copper alloys. Lead supports the formation and stability of passivation layers and, therefore, enhances the corrosion resistance of copper alloys in bio compatible lubricants [4].

- Surface layers are not only formed due to corrosion but also during friction (so-called "3rd body"). Lead is incorporated into friction layers [5], thereby increasing load capacity and reducing friction.

- When lead is used for alloying for hydraulics it does not diminish thermal conductivity of the alloy [6]. Sufficient thermal conductivity is needed for hydraulic parts and prevents them from overheating.

- As lead alloys provide low material costs and additional cost savings due to improvement of manufacturing properties, the total costs of the finished parts made of lead alloys are also lower compared to lead free alloys.

Some negative aspects of lead should be mentioned also. These include upcoming legal restrictions, but also technical disadvantages. One of the main technical shortcomings is that lead enhances hot shortness in copper alloys.

\section{STATE OF THE ART IN OIL- HYDRAULICS}

Special brass alloys are specially designed for use in lubricated sliding contacts and they are exposed to specifically high mechanical and thermal loadings. Axial piston pumps and gear pumps and hydraulics in automotive are typical examples for applications.

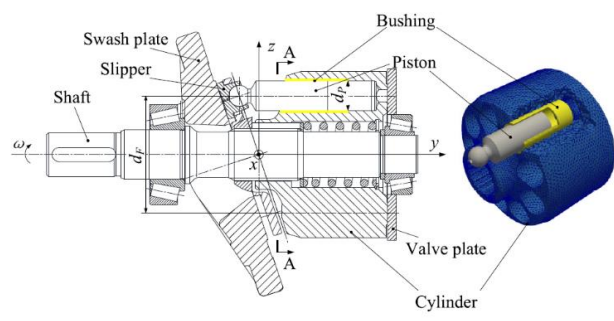

Figure 1: Scheme picture of axial piston pump [7], only main components shown, slipper, bushings and valve plate typically made of special brass

Typically, these special brass alloys contain from 20 to 30 mass- $\%$ zinc. Further on, silicon and one or more of the elements aluminium, manganese, nickel and iron are alloyed. The sum of these alloying elements amounts to 10 mass- $\%$ or even higher. Finally, the serial special brass alloys for hydraulics are alloyed with lead. Generally, these alloys consist of a matrix of $\alpha / \beta$-brass and silicides (also referred to as intermetallics or particles). These silicides are distributed within the matrix uniformly and, therefore, they are embedded both in the interior and on the grain boundaries of the grains of the brass matrix.

\section{NEW LEAD-FREE COPPER ALLOYS FOR THE OIL-HYDRAULIC INDUSTRY}

\subsection{New lead-free Special Brass Alloys for Bushings in axial Piston Pumps}

Cylinder bushings are a good example for parts whose final dimensions and surfaces must be generated by machining. Lead has a strong impact on machinability and, consequently, the influence of lead-free chemical compositions on machinability must be considered thoroughly. OTTO FUCHS investigated the machinability of different lead-free special brass alloys systematically and, therefore, regarded chip 
breaking, wear of cutting tools, machining force and surface roughness of the machined part (detailed description [8]).

Typically, special brass materials for bushings provide a heterogeneous matrix of $\alpha$ and $\beta$-phase (see Figure 2). A certain content of $\beta$-phase is required for improvement of the wear resistance of the bushings. But a major part of $\alpha$-phase is also needed, since cold drawing of the prematerial for cylinder bushings is mandatory to achieve suitable tolerances for machining and the $\alpha$-phase improves cold drawability. Nevertheless, due to the $\alpha$-phase the material is relatively soft and, therefore, is taking advantage from presence of lead which supports chip breaking. In general, such a material without lead (e.g. see Figure 2b) forms long chips (see Figure 3a) or a build-up of material on the edge of the cutting device.

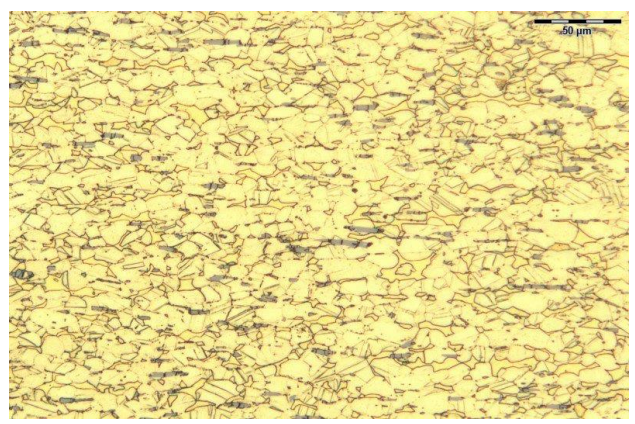

a

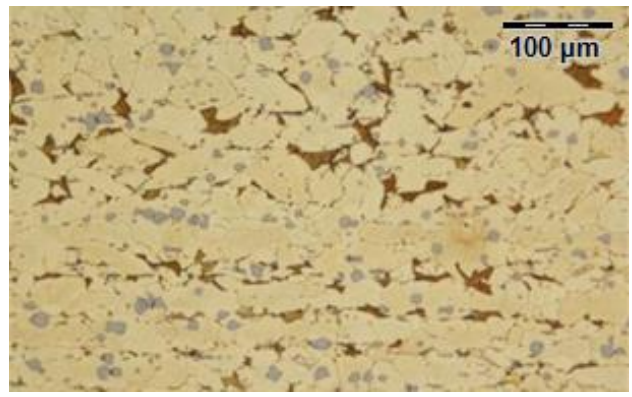

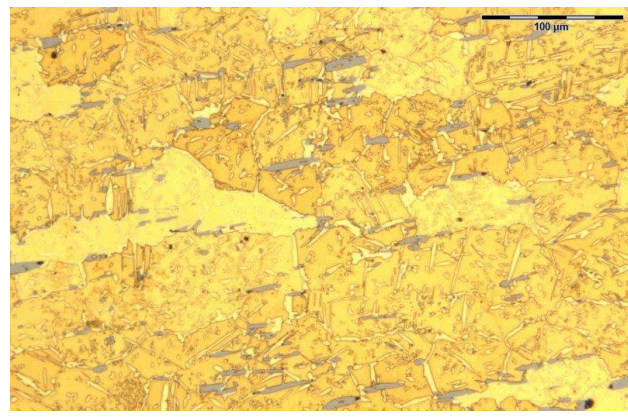

c

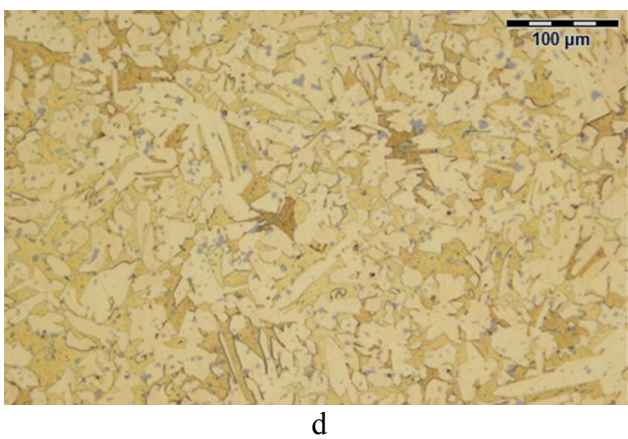

Figure 2: Microstructures of different special brass alloys for bushings in oil-hydraulics, light optical micrographs, CuZn37Mn3A12PbSi (a), lead-alloyed near- $\alpha$-alloy (OF 2297, b), lead-free near- $\alpha$-alloy (OF 2295, c), leadfree $\alpha / \beta$-alloy (OF 2299, d)

Figure 2d shows the microstructures of the recently developed lead-free special brass alloy OF 2299. Its optimized fine two-phasemicrostructures of $\alpha / \beta$-phase support discontinuous chip breaking as shown in Figure 3c. 

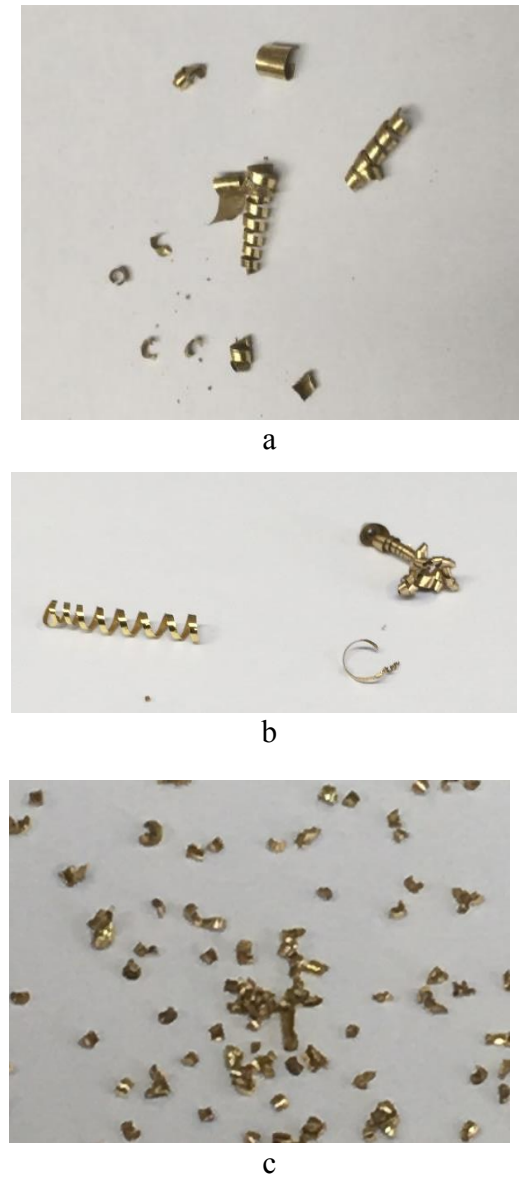

Figure 3: Chip breaking of different special brass alloys for use in hydraulics, lead-alloyed near- $\alpha$-alloy for bushings (a), lead-free near- $\alpha$-alloy for bushings (b), optimized lead-free $\alpha / \beta$-alloy (c)

So far, machinability was considered. But machinability is not the only requirement for alloys which are used in bushings in axial piston pumps. Strong friction forces appear on the bushing due to the forces acting on the piston and tilting the piston against the bushing. These friction forces are not constant but depend on the position and movement of the piston during rotation of the swash plate together with the inclination angle of the swash plate (Figure 4).

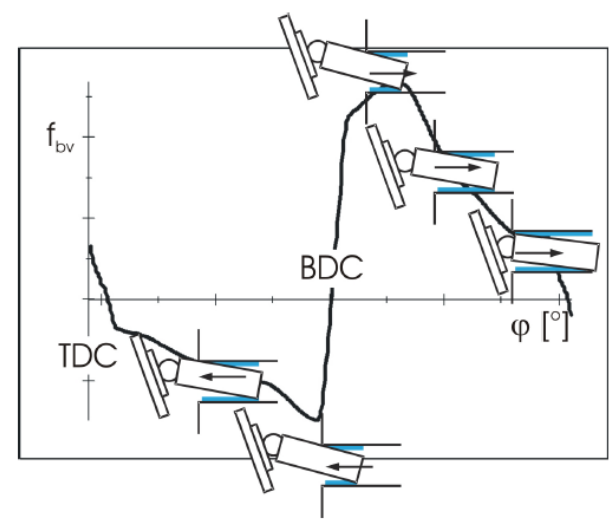

Figure 4: Typical friction progress for a pistonbushing-contact at low turning speed, top (TOD) and bottom dead centre (BDC), angle position $\varphi$ of swash plate [9]

Under friction, lead functions as a dry lubricant and, hereby, counteracts adhesion in the pistonbushing-contact. Despite all reservations against lead, a solution is yet to be found for avoiding this kind of adhesion in lead-free special brass alloys. Interestingly, investigations with different leadfree alloys show that there is no single material property dominating adhesion resistance. Adhesion resistance can be correlated neither with phase composition nor with hardness.

Under standard conditions the new lead-free alloy OF 2299 copes with the friction conditions in axial piston pumps and motors very well. But in some special cases, customers design their axial piston pumps and motors in such a way that friction in the piston-bushing-contact is particularly challenging. For this special purpose the near- $\alpha$-alloy OF 2297 has the best characteristics compared with all other lead-free alloys of this study. The good adhesion resistance of this alloy was not to be expected, as there is a relatively soft matrix of $\alpha$-phase. Although a soft surface functions as a shearing layer to support sliding against the counter surface, it is known to provoke adhesion. This is the more reason, why a combined influence of both phase distribution and chemical composition is considered mandatory for such an outstanding adhesion resistance of the alloy OF 2297. Thus, a lot of questions remain open and further investigations are planned for deeper understanding of the mechanisms which protect the alloy OF 2297 against adhesion. 


\subsection{New lead-free Special Brass Alloys for Slippers in axial Piston Pumps}

Another part of axial piston pumps and motors with particularly complex requirements are slippers (Figure 5a). Good hot formability is requested for extrusion and forging of raw parts and good machinability for production of machined parts. The flange of the slipper is joined with the sphere of the piston for achieving a hinged and free-moving assembly. Consequently, a good cold formability is needed for joining. On the one hand, the assembly is exposed to high mechanical loadings during service but on the other hand, the piston must stay free to move well in the calotte of the slipper. Under these conditions, slipper and piston need to stay connected un-detachably. High strength, fatigue strength and wear resistance are further requirements for slippers.

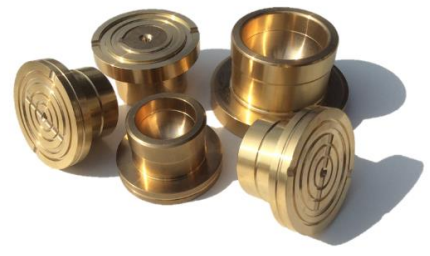

a

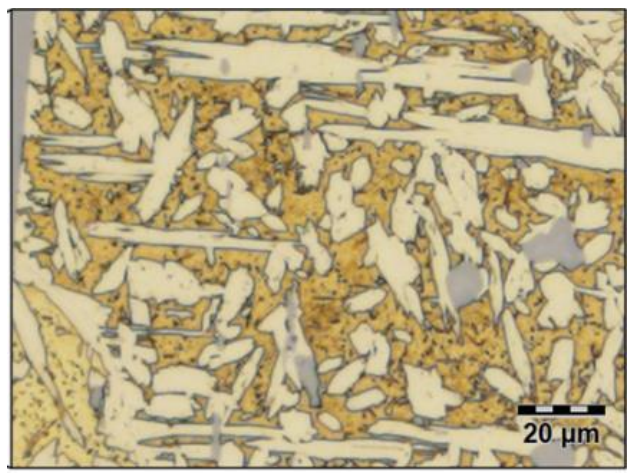

b

Figure 5: Picture of a slipper for axial piston pumps and motors (a) and micrograph, light optical microscopy, lead-free alloy OF 2299 from OTTO FUCHS (b)

Cold deformation during joining is performed close to the formability limit of the alloy. This forming process is already a challenge for leadalloyed special brass alloys. Even more challenging is this process of joining, when it is applied to lead-free alloys where the positive lubrication effect of lead in cold forming is missing. It is inevitable, that lead-free alloys must be optimized for the requirements of such a cold forming process. Investigations with different lead-free alloys have revealed that the following characteristics are needed to achieve this formability even without lead:

- Fine grained microstructures

- High content of $\beta$-phase for hot forming and strength properties

- Certain content of $\alpha$-phase for cold forming

- Micro alloying which serves for balancing different requirements

According to these requirements the new special brass alloy OF 2299 provides outstanding performance. Its microstructures show a perfect realization of the characteristics which are needed for slippers (illustrated in Figure 5b).

\subsection{New lead-free high strength alloys for distributor plates}

Lead bronze alloys provide very high lead content which ranges from 10 to 23 mass- $\%$ and, consequently, they are used when high loadings or poor lubrication is applied (e.g. for certain types of valve plates, Figure 6). Lead is insoluble in copper and forms coarse precipitations which are distributed in a matrix of pure $\alpha$-phase. The diameter of the precipitations of lead amounts to several hundred microns. These precipitations serve as a reservoir for lead as dry lubricant against friction under high loadings or poor external lubrication. During relative movement of both sliding partners lead is set free and distributed over the sliding surface.

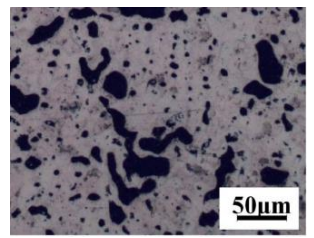

a

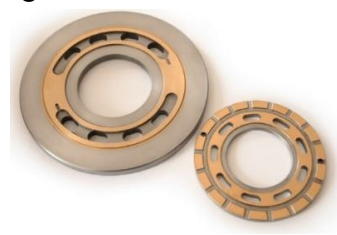

b
Figure 6: Example of a bimetal distributor plate ([10], a) and micrograph of a lead bronze typically used for friction layers of bimetal distributor plates (b, [11])

Lead bronze is used either as a bulk material or it is plated on a steel back. The steel back of the bimetal plates contributes to their high fatigue strength. So far, the use of bronze-plated steel distributor plates for axial piston pumps and 
motors with very high loadings was indispensable. Existing leaded brass alloys do not deal with such extreme loadings, properly. But the development of new lead-free special brass alloys opened new opportunities also for heavy conditions. New special-brass alloys (Table 1) cover a range of properties from standard applications to high pressure pumps and motors in a way that had not been possible before.

Table 1: Typical mechanical properties of existing and new alloys for distributor plates, room temperature

\begin{tabular}{ccccc}
\hline Properties & $\begin{array}{c}\text { Bimetal, } \\
\text { lead } \\
\text { bronze } \\
\text { layer }\end{array}$ & $\begin{array}{c}\text { OF 2212 } \\
\text { (leaded } \\
\text { brass) }\end{array}$ & $\begin{array}{c}\text { OF 2295 } \\
\text { (lead-free, } \\
\text { standard } \\
\text { applications) }\end{array}$ & $\begin{array}{c}\text { OF 2290 } \\
\text { (lead-free, } \\
\text { high } \\
\text { strength) }\end{array}$ \\
\hline $\begin{array}{c}\text { Yield } \\
\text { Strength } \\
\text { [MPa] } \\
\text { Tensile }\end{array}$ & $430-500$ & $250-350$ & $320-450$ & $500-650$ \\
$\begin{array}{c}\text { Strength } \\
\text { [MPa] }\end{array}$ & $620-850$ & $510-610$ & $550-650$ & $700-850$ \\
$\begin{array}{c}\text { Elongation } \\
\text { at break [\%] } \\
\text { Hardness } \\
\text { HBW }\end{array}$ & $>14$ & $>8$ & $>8$ & $>10$ \\
$\begin{array}{c}\text { Bending } \\
\text { fatigue } \\
\text { strength } \\
\text { [MPa] }\end{array}$ & $270-400$ & $150-180$ & $150-180$ & $210-260$ \\
\hline
\end{tabular}

The new special brass alloys OF 2295 is suitable for standard applications. Its mechanical properties are already superior to reference leaded alloys, but still too low for the use of it in new generations of piston pumps and motors with higher pressures. Under these conditions the new high strength special brass alloy OF 2290 can be applied. OF 2290 combines high strength with acceptable toughness (Table 1).

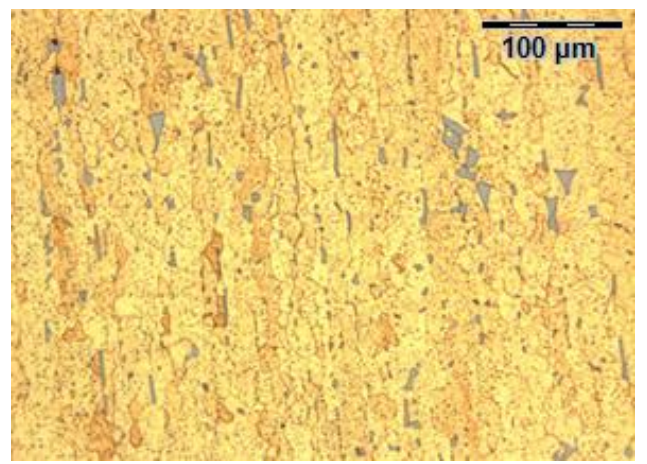

Figure 7: Micrograph of high strength lead-free special brass alloy for high strength valve plates, alloy OF 2290

The outstanding properties of alloy OF 2290 are due to the following measurements (Figure 7):
- Chemical composition containing aluminium and nickel

- Matrix of $\beta$-phase

- Fine grained microstructures

- Fine precipitations

- Several microalloying elements

\subsection{New lead-free special brass alloys for contact with environmentally compatible lubricants}

Environmentally compatible lubricants (biolubricants), e.g. esters, PAOs and PAGs are of increasing importance for oil-hydraulics. Biolubricants do have a market share of about 5 to more than $10 \%[12,13]$. The reasons for this are manifold and range from environment and health protection to increasing efficiency of components and systems lubricated with biolubricants.

Unfortunately, most copper alloys, e.g. certain special brass alloys, provide poor compatibility with biolubricants. The reason for this is that biolubricants are prone to aging. Aging of PAGs occurs by oxidisation. Esters are decomposed forming acids. The acidity of the biolubricants increases due to aging and, consequently, brass alloys are exposed to corrosion attack. Corrosion may occur in the form of dezincification or stress corrosion cracking when internal or external stresses are present $[14,15,16]$. Under these circumstances, lead contributes to the improvement of corrosion resistance which is achieved by the formation of passivation layers. Accordingly, CuZn37Mn3Al2PbSi is a standard leaded alloy for use against biocorrosion (Figure 8).

Consequently, when brass is made lead-free these alloys need to be optimized to get similar corrosion resistance as before. For that reason, different lead bearing and lead-free special brass alloys were tested using the following conditions:

- Test fluid was a mixture of engine oil, sulphuric acid and $20 \%$ of bioethanol E85.

- $\quad$ ph value of test fluid was 2.6.

- Testing temperature was $60^{\circ} \mathrm{C}$. 
Cylindrical samples were put into the test fluid for different times. After tests, change of weights of the samples was determined and sample surface was characterized with light optical microscopy.

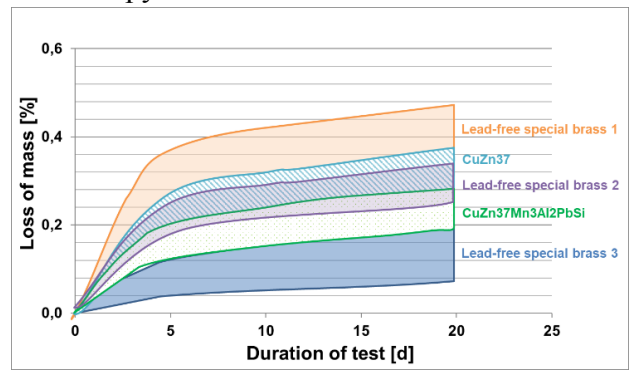

Figure 8: Loss of mass of different brass alloys, exposed to a fluid mixture of engine oil, $20 \%$ bioethanol E85 and sulphuric acid, phvalue $=2.6$, testing temperature $=60^{\circ} \mathrm{C}$, variation of duration time

In this study, CuZn37 was also tested. CuZn37 provides a matrix of mainly $\alpha$-phase. Only on the grain boundaries of the $\alpha$-phase some $\beta$-phase might be present and, then, reduces the corrosion resistance of the alloy. No alloying elements are present in $\mathrm{CuZn} 37$ which could protect against corrosion. Thus, along the $\beta$-phase corrosion can propagate into the depth and (Figure 10c) and reduce material strength significantly.

The results with $\mathrm{CuZn} 37$ underline that when giving up lead other elements are needed for passivation. For that purpose, new lead-free special brass alloys contain aluminium, manganese and other elements, additionally. Figure 9 shows the microstructures of these new lead-free special brass alloys. The microstructures range from pure $\beta$-phase to a mixture of $\alpha$ - and $\beta$-phase.

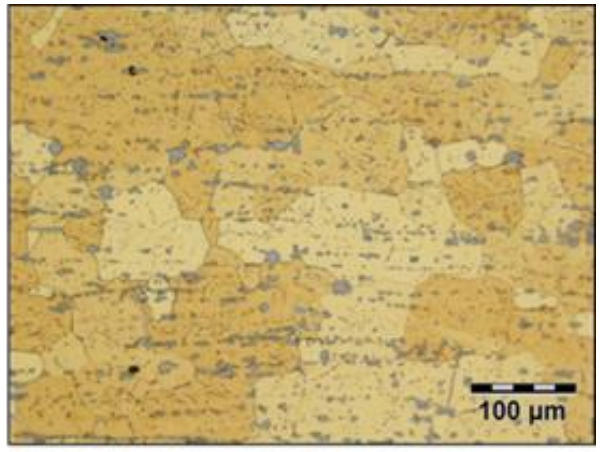

a

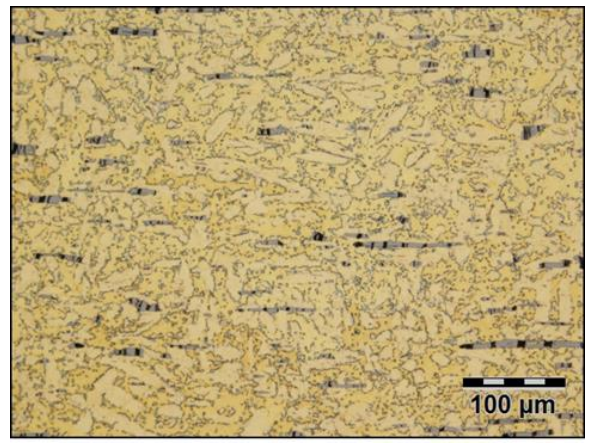

b

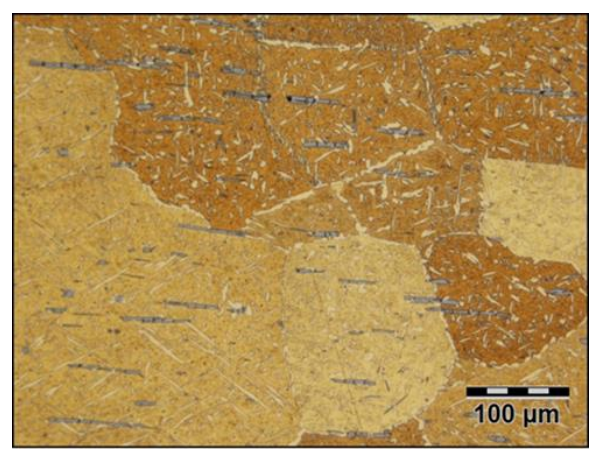

$\mathrm{c}$

Figure 9: Light optical micrographs of new lead-free special brass alloys for contact with environmentally compatible lubricants, lead-free special brass alloy 1 (a), 2 (b) and 3 (c)

The corrosion resistance against biolubricants of all these alloys is similar or even superior to

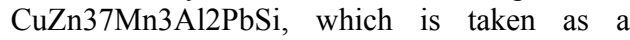
reference.

In tribological applications wear superposes corrosion and enhances material damage. Therefore, an optimized alloy for use in friction and wear with environmentally compatible lubricants need to combine both a good corrosion and wear resistance. This perfect combination is given with alloy 1 . Corrosion resistance of alloy 1 against biocorrosion is very close to reference alloy CuZn37Mn3Al2PbSi. Alloy 1 has a matrix of $\beta$-phase (figure 9a) and provides tensile strength values of up to $900 \mathrm{~N} / \mathrm{mm}^{2}$. Corrosion attack on alloy 1 is very homogeneous (Figure 10d). Consequently, alloy 1 combines extraordinary strength with remarkable corrosion resistance. 
For some other reasons, a mixture of $\alpha / \beta$-phase might be requested for application. Generally, the coexistence of $\alpha$-phase and $\beta$-phase in the matrix of brass alloys is disadvantageous for resistance to galvanic corrosion. The more important is to support passivation in these alloys and this aim was attained (Figure 10e). Thanks to alloying with additional aluminium and manganese and some further microelements the lead-free $\alpha / \beta$ special brass alloys 2 and 3 form passivation layers which are strong and dense enough to protect the surfaces as can be seen in Figure 8.

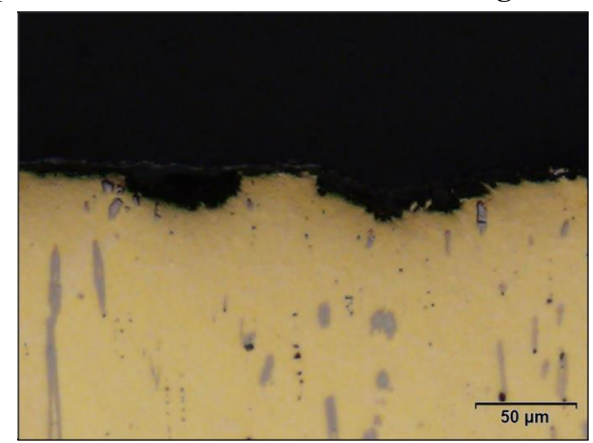

a

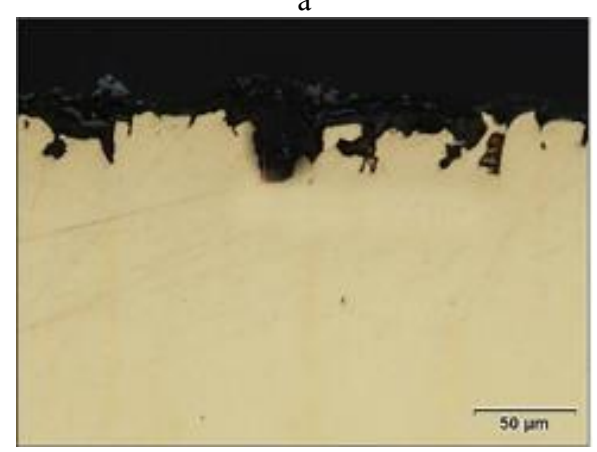

b

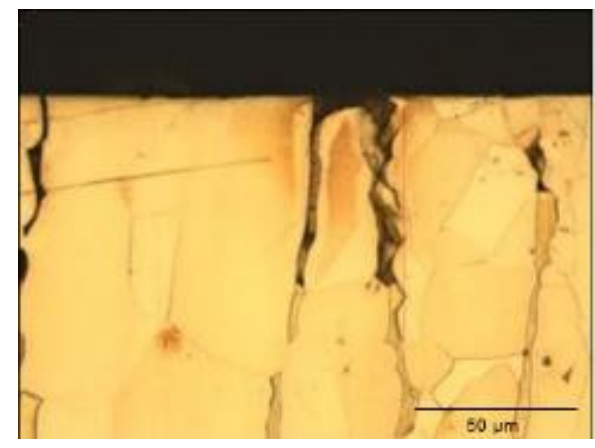

c
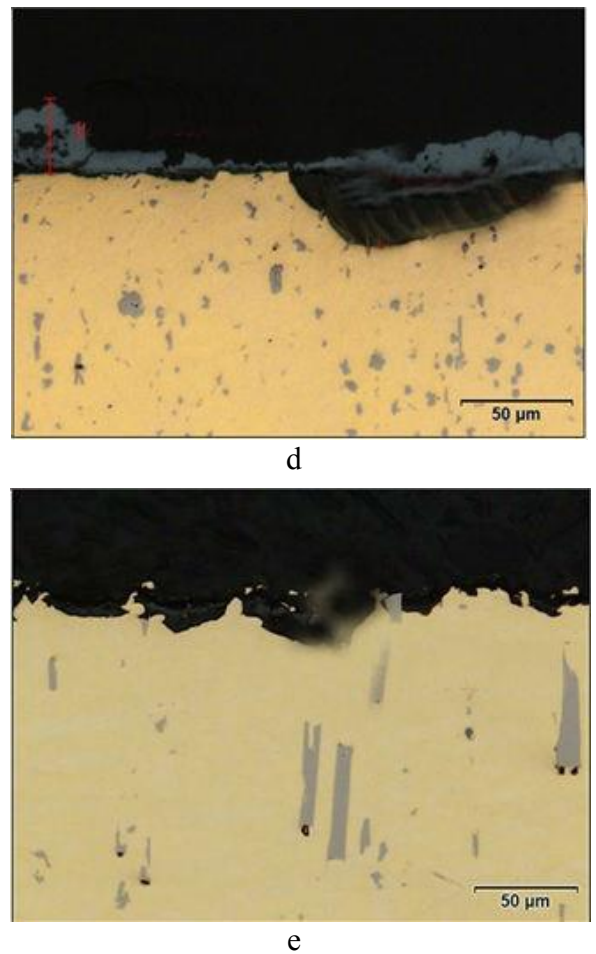

Figure 10: Light optical micrograph of different brass alloys after corrosion testing, CuZn37Mn3Al2PbSi (a), CuZn37 (b+c), alloy 1 (d), alloy 2 (e)

\subsection{Further lead-free applications for hydraulics and new opportunities}

There are many more applications of special brass alloys in oil-hydraulics. Axial piston pumps are not only equipped with slippers, valve plates and cylinder bushings, they also contain holding segments, ball guides and bearing shells. All these parts are made of special brass alloys, too. Not only axial piston pumps, but inner gear pumps are equipped with parts made of special brass, e.g. thrust bearings and crecents.

All these parts open a wide field of further applications for the new lead-free special brass alloys described in this publication.

\section{SUMMARY}

Due to the banishment of lead from copper alloys lead bearing alloys which have been proven and used for application in hydraulics for decades are to be replaced. Using the examples of cylinder 
bushings, slippers and valve plates for axial piston pumps it was demonstrated which challenges need to be tackled in replacing leaded alloys with new lead-free alloys.

Lead as an alloying element is beneficial for a lot of different properties like casting, machining and forming, but also for mechanical properties, low friction, corrosion and wear resistance. All these requirements can be fulfilled with new leadfree brass alloys which was shown in this article. New lead-free alloys especially for requirements from applications in oil-hydraulics have been developed. These new alloys are available on the market and provide a technical performance which is similar or even superior to existing alloys containing lead. The outstanding properties of the new alloys were achieved through a combination of adjustment of chemical composition, heat treatment and the resulting microstructures. Maybe, in the future it will be also possible to conquer new applications with these new alloys where the properties of conventional leaded alloys would not have been sufficient.

\section{REFERENCES}

[1] Deutsches Kupferinstitut:

https://www.kupferinstitut.de/en/consultation/ copper-wiki/details/article/was-bewirkt-daslegierungselement-blei-pb.html [20-08-2019]

[2] Brunhuber E (1959) Schmelz- und Legierungstechnik von Kupferwerkstoffen. Edition, 1. Publisher, Schiele \& Schön, 1959

[3] PHOENIX Contact GmbH\&Co. KG and HARTING KGaA (2015) Original Application for Exemption Renewal Request, 16.01.2015

[4] URL:

https://elv.exemptions.oeko.info/fileadmin/user _upload/Consultation_2014_1/Ex_3/E3_30 _supplier_8_corrosion_journal-bearing.pdf [20-08-2019]

[5] Paulus A (2017) Reaktionsschichtbildung auf bleifreien Bronze- und Messingwerkstoffen im Kontakt von Zylinder und Steuerscheibe einer Axialkolbenpumpe. Dissertation, RWTH Aachen

[6] Pawlek A, Reichel K. (1956) Z. Metallkunde 47, pp. $347-56$

[7] Jihai J, Kelong W, Zebo W, Yi S (2019) IEEE Access 7, pp. 24971-24977

[8] Nobel C, Klocke F (2013) Entwicklung einer Hochleistungszerspanung für schwer zerspanbare bleifreie Kupferknetund -gusslegierungen. Schlussbericht des geförderten Vorhabens IGF16867 N

[9] Murrenhoff H, Scharf S (2006) International Journal of Fluid Power 7 No. 3, pp. 13-20

[10] KUGLER BIMETAL: https://www.hannovermesse.de/produkt/bimetal -verteilerplatte/170413/N1374441 [31-10-2019]

[11] Zhang X, Ren X-y, Hong X, Gaoc X-y (2019) RSC Adv., pp. 34972-34985

[12] Luther R (2011) Bioschmierstoffe für den kommunalen Fuhr- und Maschinenpark. Kongress NawaRo-Kommunal Berlin, 22./23.11.2011

[13] Bressling J (2012) Life Cycle Assessment der alterungsbedingten Umweltverträglichkeit biogener Hydraulik- Schmierstoffe. Dissertation, RWTH Aachen

[14] Werner M. (2000) Das Betriebs- und Alterungsverhalten schnell abbaubarer Hydrauliköle. Dissertation, RWTH Aachen

[15] Göhler O.-C., Schmidt M. (2004) Einfluss der Alterung auf das tribologische Verhalten umweltverträglicher Ester. O+P 48, pp. 322-326

[16] Murrenhoff H (2012) Bioschmierstoffe - Ein Überblick zu Vor- und Nachteilen der eingesetzten Produktgruppen. Bioschmierstoffkongress der FNR, Oberhausen 